reasons. Farmers demanded weather forecasts because adverse weather could lead to economic doom if crops were not harvested before a hail storm. International maritime cooperation was stimulated with one of the first economic analyses, which showed that marine meteorological charts produced annual savings in the 1800 s of between $\$ 40 \mathrm{~m}$ and $\$ 60$ m worldwide. ${ }^{5}$

Airlines recognised the importance of accurate weather forecasts for safety and profit. In contrast, governments, industry, and the public have not clamoured for better forecasting of disease as the economic importance of improved prediction may not be obvious. But, given the current costs of care, information concerning current and future disease patterns are critical for planning individual and industrial strategy. Moreover, the accurate monitoring of disease is important for governments as they have to decide how to allocate their scant resources for health care.

We are fast approaching the twenty first century with techniques towards monitoring and forecasting disease patterns that have changed little since the $1800 \mathrm{~s}$. These need revamping: the model of weather forecasting may be the way forward.

RONALD E LAPORTE Professor

Department of Epidemiology,

University of Pittsburgh,

Pittsburgh, PA 15025,

USA

1 Facts on File 1992;27:629.

2 World Almanac. New York: Shripps Howard Company, 1993.

3 Whitnah DR. A history of the United States weather bureau. Urbana: University of Illinois Press, 1961.

Hughes P. A century of weather service: a history of the birth and growth of the national weather service, 1870-1970. New York: Gordon and Breach, Science Publishers, 1970.

5 LaPorte RE, McCarty DJ, Bruno G, Tajima N, Baba S. Counting diabetes in the next millennium: application of capture-recapture. Diabetes Care 1993;16:528-34.

6 LaPorte RE, McCarty DJ, Tull ES, Tajima N. Counting birds, bees and NCDs. Lancet 1992;339:494-5.

7 Directors of the WHO Non-Communicable Disease Collaborating Centres and Key Officials. Needed: universal monitoring of all serious diseases of global importance. Am f Public Health 1993;83:941-3

8 Birkhead G, Chorba TL, Root S, Klaucke DN, Gibbs NJ. Timeliness of national reporting of communicable diseases: the experience of the national electronic telecommunications system for surveillance. Am f Public Health 1991;10:1313-5.

\title{
AIDS: global lessons from a global epidemic
}

\section{New international threats demand international responses}

The central lesson of the global epidemic of HIV infection is that the world is still extremely vulnerable to the emergence and spread of infectious agents. Yet despite this, action to prepare the world for the next pandemic has been hesitant, grounded in traditional surveillance methods and limited by preglobal thinking about the ecology of microbial threats to health. The response of science, public health, and society to the emergence and dissemination of new diseases has been too narrow.

Global HIV has spread from an estimated 100000 people infected worldwide in 1980 to nearly 20 million by early $1993 .{ }^{1}$ This has shown us how newly emerging pathogens spread globally-by enormous movements of people, the universality of sexual exchange, an international traffic in blood products, and the international epidemic of drug misuse. The dramatic increase in movements of people, goods, and ideas during the past quarter of a century has increased the opportunities for infectious agents to transcend borders. Paradoxically, two divergent directions of movementurbanisation and entry into previously uninhabited landshave both facilitated the emergence of new disease. ${ }^{2}$

A cluster of fortunate circumstances led to the relatively rapid recognition of the HIV/AIDS pandemic within a decade after the start of its widespread dissemination. Had the latency from infection to disease been longer, had human retrovirology not been sufficiently developed, had the pathogenic action of HIV led only to increases in common illnesses and cancers rather than to a very unusual syndrome, had the syndrome's occurrence been more initially diffused in the population, or had it not occurred in an industrialised country with an unparalleled capacity for national surveillance and communication, then the discovery of HIV/AIDS could easily have been delayed for an additional five to ten years, with enormous consequences for public health.

What of the future? We can be sure that expanding human influences on the natural environment at local, national, and even global levels will favour increased contact between humans and pathogens which are presently unknown or of limited geographical range or affect only other species. Once such pathogens enter a human population the increasingly transnational organisation of our economic, social, cultural, and political world gives them a chance for rapid spread.

More than 10 years of AIDS should have led to a new era of thinking about global vulnerability to new pandemics, but despite the excellent recent report by the United States Institute of Medicine, an aggressive and appropriate response has been slow to develop. ${ }^{3}$ By contrast to the dynamic nature of the problem, current proposals seem static. These have included establishing sentinel "centres of excellence" around the world and similarly entrusting the World Health Organisation with the responsibility for developing and coordinating an early warning system for the emergence of new diseases.

Unfortunately, the world remains unprotected by any semblance of a global system for anticipating, seeking, and identifying new microbial threats to health, let alone responding coherently to them. The central features of such a system would include

- global scientific leadership to recognise and publicise the danger of perpetuating the current ad hoc and highly fragmented disease surveillance system

- recognition that only a truly international system can be effective

- recognition that many factors affect the emergence of disease, including climate and environmental change; socioeconomic, political, and cultural processes; migration; commerce and shipping; and tourism

- a means of predicting where new microbial threats may emerge, based on an ecological understanding of conditions which foster such developments-with the focus more on the milieu than on the microbe

- a rethinking of surveillance strategies to include an analysis of how recent new pathogens have been identified and consideration of which types of data would most usefully identify changes in health patterns. Many disciplines and techniques (such as molecular biology, mathematical modelling, and remote sensing) must be combined with the perspectives of workers in primary care and local health. Collaboration is needed with social scientists, economists, and 
psychologists about how to identify new patterns. Economic, tourist, travel, and migration data will be needed, along with surveys of health providers and informants in the community. A "Maginot Line" approach, based on a few large laboratories, cannot be the centrepiece of this type of free ranging data network, whose objective is to detect perturbances that suggest a change in health status.

A new global rapid response system will be needed to investigate potential new threats to health supported by epidemiological, clinical, and laboratory services. In the modern world national boundaries cannot be an impermeable barrier to such targeted investigations.

Global threats require global thinking and leadership. How we define the problem will determine what we do about it. The time has come to give real priority to the worldwide anticipation, detection, and response to new microbial threats to health. Early detection of the next (already ongoing?) new pandemic will handsomely repay the necessary investment. Global epidemics, including their prevention, recognition, and response, are likely to be an increasing part of the new agenda for international health.

JONATHAN MANN Director

Francois-Xavier Bagnoud Center for Health and Human Rights,

Harvard School of Public Health,

665 Huntington Avenue, Room 1208C,

Boston, MA 02115,

USA

Infectious Diseases,

Mt Auburn Hospital,

330 Mt Auburn Street,

Cambridge, MA 02238,

USA 1 Mann JM, Tarantola D, Netter T, eds. AIDS in the world. Cambridge, MA: Harvard University
Press, 1992.

2 Gibbons A. Where are "new" diseases born? Science 1993;261:680-1.

3 Institute of Medicine. Emerging infections: microbial threats in the United States. Washington, DC: National Academy Press, 1992.

\section{Poor children in rich countries}

\section{Markets fail children}

Unicef's annual report for 1993, The Progress of Nations, ${ }^{1}$ makes depressing reading. In some industrialised countries the gains made during the 1970s are slowing or even reversing. The picture varies among countries, but a clear underlying trend is apparent, with differentiation between countries with an Anglo-American culture (the United States, Canada, Britain, Australia, and New Zealand) and those with a continental culture (such as Germany, France, and the Scandinavian and Benelux countries). During the 1980s countries with an Anglo-American culture experienced falls in an index of the social health of children (measured as a combination of infant mortality, government spending on education, the rate of suicide among teenagers, and income distribution) while countries with a continental culture experienced improvements.

The reasons for this difference lie in the differing responses to the slowing of economic growth during the 1980s. These issues are explored in detail in an accompanying volume, Child Neglect in Rich Nations, ${ }^{2}$ in which the author lays the blame firmly at the door of the laissez faire, market based policies introduced by the Anglo-American countries during this period.

These countries, with their tradition of low levels of education and deregulated work places, have pursued policies that favour an expansion of low income jobs in the service sector. In the United States, the average earnings of men fell by $19 \%$ between 1973 and 1987 . Large numbers of women entered the labour market, mostly in low paid part time jobs, so that, despite the number of married women in employment rising by a third over this period, family income rose by only $6 \%$. ${ }^{2}$ Similar phenomena occurred in Britain and Australia. In contrast, continental countries invested in people, with extensive training programmes and policies on minimum wages. As a result, hourly earnings increased in real terms throughout the period in France and Germany. ${ }^{3}$

The two groups of countries also differ in their response to child poverty. Redistribution of income in the AngloAmerican countries has typically been through a shift from progressive to regressive taxes, exemplified by the fall in income tax and rise in value added tax in Britain. This, taken with cuts in benefits, has served to make the poor worse off. In contrast, the continental countries have sought to redistribute income in the opposite way, from the rich to the poor. The consequences of the taxation and benefit systems of different countries are most clearly seen by comparing the percentage of children living in poverty (defined by Unicef as below $40 \%$ of the median family income) in each country. The United States is far above other industrialised countries at $21 \%$. Next come the other Anglo-American countries (Canada, Britain, and Australia) at about $9 \%$. France, Germany, the Netherlands, and Sweden are all below $5 \% .^{2}$

Falling wages have combined with increasing job insecurity to drive people to work much harder. The constant restructuring of industry and the diminishing public sector have meant that no one can be complacent about his or her long term employment. As a result, people in the Anglo-American countries are working much longer hours and taking fewer holidays. ${ }^{2}$ This differs from the situation on the continent, where working long hours is seen as an admission of incompetence, and has greatly affected the time that parents can spend with their children. One study has shown that the total contact time between parents and children in American families has fallen since $1960 .{ }^{4}$ The quality of this contact is also affected as exhausted parents collapse after an increasingly stressful day at work.

Child poverty and reductions in parental contact are much greater when there is only one parent. Again, the increases in family breakdown are much higher in the Anglo-American countries than elsewhere. A quarter of all American children now grow up in a family without a father-a proportion that has doubled within one generation. The implications are both financial and emotional. In Britain and the United States about $40 \%$ of divorced fathers pay no maintenance. Britain's new Child Support Agency is designed to redress this, but it has been more successful in reducing the welfare bill than improving the lot of children. Indeed it appears to have driven children of second families into poverty. The emotional impact of absent fathers is apparent from studies showing that 